\title{
Public Health Education in India and China: History, Opportunities, and Challenges
}

\author{
Shrikant I. Bangdiwala, $\mathrm{PhD},{ }^{1}$ \\ Joseph D. Tucker, MD, MA, ${ }^{2}$ \\ Sanjay Zodpey, MD, PhD, ${ }^{3}$ \\ Sian M. Griffiths, MB BChir, MA, FRCP, ${ }^{4}$ \\ Li-Ming Li, ${ }^{*} \mathrm{MD}, \mathrm{PhD},{ }^{5}$ \\ K. Srinath Reddy, ${ }^{\dagger} \mathrm{MD}, \mathrm{DM}, \mathrm{MSc},{ }^{3}$ \\ Myron S. Cohen, MD, ${ }^{1}$ \\ Miriam Gross, MIA, PhD, ${ }^{6}$ \\ Kavya Sharma, PGDHHM, ${ }^{3}$ \\ Jin-Ling Tang, MD, MSc, $\mathrm{PhD}^{4}$
}

\begin{abstract}
Public health education in China and India has a long history that has been both deeply responsive to the unique needs and medical traditions of each country, and sensitive to global influences. The history of public health education in China reaches back several centuries, with substantial input from American and European organizations during the Republican Era, 1911-1949. In India, centuries-old health care traditions were influenced during the colonial period by the British Empire prior to independence in 1947. Political upheaval in both countries during the 1940s further impacted the public health systems as well as public health education.

The primary goal of this review is to outline public health education in India and Mainland China, with a focus on describing the historical systems and structures that have promoted the development of formalized public health education. We examine current challenges, and analyze opportunities for improvement. Health
\end{abstract}

\footnotetext{
${ }^{1}$ University of North Carolina at Chapel Hill, USA.

${ }^{2}$ Harvard Asia Center and Harvard Medical School.

${ }^{3}$ Public Health Foundation of India, New Delhi.

${ }^{4}$ School of Public Health and Primary Care, Chinese University Hong Kong.

${ }^{5}$ Peking Union Medical College and School of Public Health, Peking University.

${ }^{6}$ University of Oklahoma.

*Senior Author for China.

${ }^{\dagger}$ Senior Author for India.
}

Corresponding Author Contact Information: Shrikant Bangdiwala at kant@unc.edu; University of North Carolina at Chapel Hill, 137 Franklin St. Ste. 203, Campus Box 8030, Chapel Hill, NC, USA. 
reforms in China and India need to consider new and modern models for public health education, perhaps in independent faculties of public health, to reinvigorate public health education and strengthen the position of public health in addressing the health challenges of the $21^{\text {st }}$ century.

Keywords: China, India, public health, education, capacity building, training

Recommended Citation: Bangdiwala SI, Tucker JD, Zodpey SM, Griffiths S, Li L-M, Reddy KS, Cohen MS, Gross M, Sharma K, Tang J-L. Public Health Education in India and China: History, Opportunities, and Challenges. Public Health Reviews. 2011;33:204-24.

\section{INTRODUCTION}

This issue of Public Health Reviews on the theme of "Education in Public Health" aims to provide a broad scope analysis of the history, current status and challenges for future development of educational and accreditation systems for the public health workforce needed in the coming decades. China and India are the most populous countries in the world and are rapidly developing emerging global economic and political powers. Based on the Human Development Index of the World Bank (Table 1), both have been developing rapidly since 1980, with China outpacing India, and currently higher than the global average. An understanding of public health education history and current efforts in these two important countries may shed some light on how public health education can be prioritized in other developing nations.

\section{Table 1}

Human Development Index for China and India, compared to the World, from 1980 to 2010

\begin{tabular}{c|c|c|c}
\hline Year & China & India & World \\
\hline 1980 & 0.368 & 0.320 & 0.455 \\
1985 & n.a. & n.a. & 0.486 \\
1990 & 0.460 & 0.389 & 0.526 \\
1995 & n.a. & n.a. & 0.554 \\
2000 & 0.567 & 0.440 & 0.570 \\
2005 & 0.616 & 0.482 & 0.598 \\
2010 & 0.663 & 0.519 & 0.624 \\
\hline
\end{tabular}

Source: The World Bank (2011) World Development Indicators, Available from URL: http:// data.worldbank.org/indicator (Accessed 7 September, 2011). 
Public health in the $21^{\text {st }}$ century faces challenges on three fronts. First, there is an increasing recognition of the growing economic and social impact of chronic diseases on an ageing population. Changing demographics and increased longevity in developing countries have increased the numbers of those at risk for chronic diseases, thereby necessitating health systems to evolve in order to meet this new challenge. China has almost nine years higher life expectancy at birth than India (Table 2). Second, although there is an acknowledgement that the delivery of quality health services depends on the availability of a robust and efficient workforce which embodies the principles of primary health care, there is increasing concern about limited human resources and "brain drain", workforce migration from developing to developed countries. Third, the increasingly strapped budgets of public health sectors increase the importance of cost-effective interventions and implementation research. The rising costs of basic public health interventions mean that value and costs must be more explicitly accounted into planning and models.

\section{Table 2}

China and India country profiles on selected human development indicators

\begin{tabular}{l|c|c}
\hline & China & India \\
\hline Total population (2009, millions, World Bank Database) & 1,331 & 1,155 \\
\hline GDP per capita (2008 PPP US\$) & 7,206 & 3,354 \\
\hline Adult literacy rate (both sexes) (\% aged 15 and above) & 94.2 & 68.3 \\
\hline Expenditure on education (\% of GDP) (\%) & 2.3 & 3.2 \\
\hline Mean years of schooling (of adults) (years) & 7.5 & 4.4 \\
\hline Life expectancy at birth (years) & 73.5 & 64.4 \\
\hline Under-five mortality (per 1,000 live births) & 21 & 69 \\
\hline Maternal mortality ratio (deaths of women per 100,000 live births) & 45 & 450 \\
\hline Expenditure on health, public (\% of GDP) & 1.9 & 1.1 \\
\hline
\end{tabular}

Source: The World Bank (2011) World Development Indicators. Available from URL: http://data. worldbank.org/indicator (Accessed 7 September, 2011).

Regarding public health education specifically, the current expenditure on education as a percent of GDP is only 2.3 percent in China and 3.2 percent in India (Table 2). Expenditure on health as a percent of GDP is also quite small, 1.9 percent in China and 1.1 percent in India (Table 2). Existing systems and models must be modernized and optimized to modern 
standards of public health education in the United States, Europe and elsewhere. Strengthening health systems through structural changes and improving human resources can help address the challenges facing public health education in the $21^{\text {st }}$ century.

This article first examines the Chinese and then the Indian contexts. In each case, we review the history of public health teaching, current challenges, and potential opportunities for reform and improvement of public health education.

\section{PUBLIC HEALTH EDUCATION IN CHINA}

The importance of public health and public health education reaches back to ancient China. The Yellow Emperor's Classic of Internal Medicine stated, "The superior physician helps before the early budding of the disease. The inferior physician begins to help when the disease has already developed." The twentieth century saw remarkable developments in Chinese public health education, including some unique systems merging clinical and public health implementation (health demonstration projects, barefoot doctors) that have drawn global attention. The transformation of the cooperative medical system alongside the phasing out of the barefoot doctor system has ushered in a new period of more dedicated public health education, training, and scholarship.

\section{History of Public Health Education in China}

Prior to 1949 , there were limited formalized public health systems or public health education structures. The central government established a Sanitary Department in $1905,{ }^{2}$ but many public health functions were implemented by police and other interdisciplinary groups. Municipality public health administrations followed German models that designated health work, often compulsory quarantine, as the domain of the police. ${ }^{3,4}$ Early public health campaigns were organized by interdisciplinary working groups rather than individuals with specialized public health education. During 1915-1916, a series of massive public health education campaigns were organized by the Joint Council on Public Health Education, an interdisciplinary group composed of both Chinese and Western members. ${ }^{5}$

The first formalized public health education in twentieth century China started at Peking Union Medical College (PUMC), the flagship Chinese medical school. The Rockefeller Foundation and the China Medical Board within Rockefeller funded the establishment of PUMC in 1917. In 1924, 
John B. Grant started a Public Health and Preventive Medicine Department within PUMC, arguing for an integrated training curricula that would bring together clinical medicine and population health. ${ }^{6}$ This holistic medical model focused on affordable and widespread health care in rural and urban areas. Recognizing the need for more formal training, Grant initiated education programs for public health officials. ${ }^{7}$

After the start of the National Ministry of Health in 1928, one of its four foci was training health personnel including a focus on public health skills. The Ministry also provided a blueprint for establishing provincial health bureaus that included an education and propaganda department. The Ministry set up a central field station to develop strategies for rural disease control, treatment, and education and then launched sub-field stations in 35 locations in eight provinces. The field station also started a postgraduate training program for public health-oriented jobs like public health officer, sanitary inspector, and public health teachers for schools. ${ }^{4}$

After the founding of the People's Republic of China in 1949, the public health education system, like all the educational structures, was substantially transformed. Although compulsory primary education systems were established during this time, colleges and postgraduate centers for learning were substantially downsized during peak revolutionary periods: the Great Leap Forward (1958-1959) and the Cultural Revolution (1966-1976). Despite the lack of formal training systems, there were several remarkable public health programs during this time, in large part reflecting Mao's commitment to "serve the people." Most were structured as patriotic health campaigns because of their connection to national political campaigns (Figure 1). They focused on mass mobilization, balanced preventive and curative strategies, and incorporated elements of traditional Chinese and Western medicine. Their most impressive successes included nearly eradicating sexually transmitted diseases through massive treatment campaigns and structural interventions, mass immunization campaigns, and large improvements in maternal-infant care that greatly diminished infant mortality. ${ }^{8}$

Due to close ties with the Soviet Union, China introduced a comprehensive public health system based on the Soviet model in 1953, including forming undergraduate hygiene departments and anti-epidemic stations. ${ }^{5}$ There were three main levels of anti-epidemic station within the public health system - provincial, municipal or prefecture, and county or district. By the end of 1965, all 29 provinces had anti-epidemic disease stations with analogous structures for the railway, mining industry, and large enterprises. This was mainly a biomedical model of public health, and 
public health education included five major disciplines, namely, epidemiology, school hygiene, occupational hygiene, food hygiene, environmental hygiene and radiation hygiene.

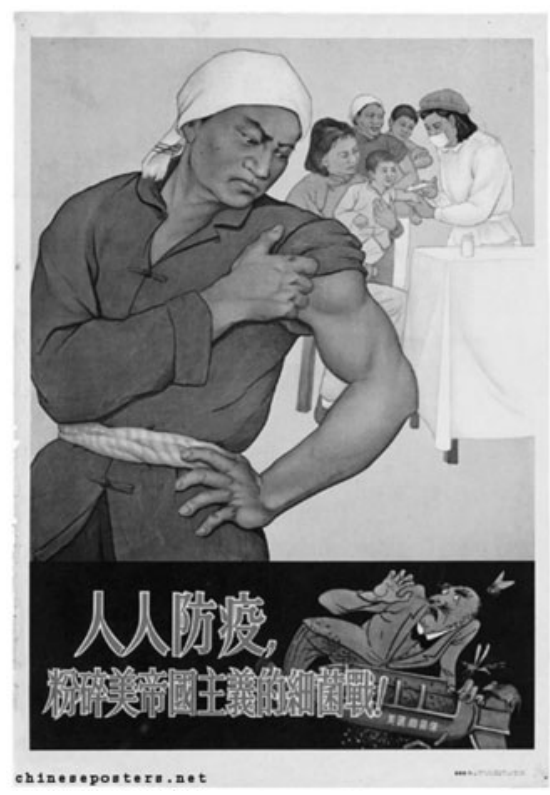

Fig. 1. "Everyone must take precautions against epidemics to smash the germ warfare of American imperialism."

Source: The IISH/Stefan R. Landsberger Collections. ${ }^{27}$

China's 'barefoot doctor' system was instituted in the late 1960s, largely taking shape following a speech by Mao Zedong in 1965 emphasizing rural health. The barefoot doctors completed secondary school and then received three to six months of training at a commune level hospital. ${ }^{9}$ Barefoot doctors represented a hybrid between clinical physician and public health practitioner, implementing a number of measures to improve public health. They provided vaccines, created water and sanitation systems, improved stoves and toilets, provided basic medical care, assisted in family planning policies, and collected information about epidemics. ${ }^{10}$ As such, they were the foundation of a three-tiered Cooperative Medical System, reporting upward to commune health centers who reported up to county hospitals.

During the period from 1949 to 1978, the Chinese government made great strides in achieving good health and tackling major health problems. 
During this period, approximately 22 percent of the world's population benefitted from only one percent of world total health expenditure. ${ }^{11}$ From 1952 to 1982, average life expectancy increased from 35 to 68 years; infant mortality decreased from 250 to 40 deaths per 1000 live births; and the overall population increased from 582 million in 1953 to over a billion in $1982.12,13$

The marketization of China's economy during the 1980s had important effects on both the content and distribution of public health resources. This process reduced central government public health investment, dismantled the Cooperative Medical System, and decentralized the public health system. ${ }^{14}$ The barefoot doctor system was dismantled alongside the commune system and in 1985, the Ministry of Health officially cancelled the title. ${ }^{9}$ By then only five percent of people were covered by the Cooperative Medical System, and markets were increasingly dictating the distribution and organization of health services. ${ }^{15}$ Inequalities in access to health services were exacerbated by these trends as public health resources were redirected away from rural areas and economic development progressed more rapidly in urban areas.

More recently, China has launched several programs to reform its health care system, which include strengthening its public health systems. In 2009 the China Health Reform Plan promised to spend 850 billion Renminbi in three years and re-establish a universal primary care system. ${ }^{16}$ The broader impact of health reform has catalyzed improvements in public health education at several levels and is discussed in more detail below.

\section{Current public health training in China}

Formal structures of undergraduate and graduate-level public health training re-emerged in 1978 in China, with much of the curricula and format deriving from international models. ${ }^{17}$ Postgraduate training focused on training researchers until the Ministry of Education started Master of Public Health (MPH) programs. Typical undergraduate public health curriculums include training in epidemiology, health statistics, nutrition and food hygiene, environmental and occupational health, school hygiene, and health toxicology, social medicine and health management, child adolescent and maternal health, and health chemistry. Public health and pre-clinical medical students take a common core curricula during the first several years of training. ${ }^{18}$

There are now thousands of public health undergraduates and graduate students pursuing formal public health education at schools of public health in China. A typical bachelors program in public health lasts five years after 
secondary school. Four years of basic science and clinical requirements are generally followed by one year focused on various aspects of public health. Core departments in a school of public health include the following: epidemiology and health statistics, social medicine and health management, occupational and environmental health, nutrition and food hygiene, child adolescent and maternal health, health toxicology, and health chemistry. ${ }^{17,19}$ There are also public health diploma programs, certificate programs and associated short-term training opportunities at many medical schools in China.

The focus of current public health training efforts has been on bachelors and masters level training, with relatively few programs focused on training $\mathrm{PhD}$ candidates and postdoctoral fellows. There are notable exceptions, however, such as the Peking University School of Public Health, which have placed a greater focus on long-term training and postgraduate research.$^{20}$ Many final year students or trainees have the opportunity to do practicums at centers for disease control and prevention (CDCs) or hospitals during their final year of training.

\section{Centers for Disease Control}

The CDCs are the major modern public health institution in China. The system of CDCs was established in China in 2002 by the Chinese Academy of Preventive Medicine, creating a nationwide infrastructure for disease control and prevention. ${ }^{21}$ Precursor anti-epidemic stations were turned into CDCs at all levels - county, city, province, and nation. The national China CDC resides in Beijing and a parallel organization has been established in each provincial capital. The China CDC as an institution embodies a modern broad concept of health, including disease prevention and control, and the five major public health disciplines. In order to strengthen staff training, the China CDC also set up a Chinese Field Epidemiology Training Program (CFETP). Among the fifteen core responsibilities of the China $\mathrm{CDC}$, one is explicitly related to training, focusing on ensuring training for subordinate personnel on disease control and prevention. ${ }^{22}$

Following graduation from a school of public health, the most common place of employment for public health graduates is a CDC, with smaller numbers entering a hospital, non-governmental organization, medical school, research institute, administration, or other work unit. Generally, the CDCs and the public health training system are organizationally and administratively distinct, with the exception of the national CDC that has masters and $\mathrm{PhD}$ training programs available through the CDC. Public health staff at CDCs have varying levels of training, ranging from county- 
level staff who may only have a three-year diploma to provincial and national level staff who often have advanced degrees in public health. ${ }^{20}$ Since schools of public health have a strong interest in research, a gap between public health practice and public health education has emerged in China. ${ }^{20}$

\section{Catalysts for Public Health Education Change}

Public health education in China is dynamic, responsive both to international trends and changing local contexts. Traditional Chinese medical school curricula are being restructured at many institutions, providing an important opportunity to expand the role of public health education. The China Medical Board, integrally involved in early public health education at PUMC, continues to play an important role in promoting medical education reform and public health education. CMB has offices at 13 Chinese medical schools, supporting a number of public health training programs, ranging from Masters in Medical Education to rural nursing training programs.

Regional collaboration within China and across Asia also promotes changes in public health education. The Asian-Pacific Academic Consortium for Public Health (www.apacph.org) provides one avenue for such work, sponsoring the journal Asia Pacific Journal of Public Health, holding an annual conference, developing collaborative research projects, building multi-country leadership, and holding joint curriculum development programs. ${ }^{23}$ Within China, deans of schools of public health meet regularly to share ideas and experiences for improving public health education. A conference in late 2009 brought together leaders from public health schools in China to discuss challenges and responses to improving public health education in the country. ${ }^{24}$

Perhaps most importantly, China's health reform provides opportunities for renewing commitment to improving the public health infrastructure and training system. This reform system explicitly addresses equity, drawing on the WHO conception of "public health for all." Professor Li-Ming Li at the Chinese Academy of Medical Sciences and PUMC has been a strong proponent, articulating how health reform can catalyze gains in public health. ${ }^{25}$ The new public health model which acts as one of the four beams that rest on eight columns, a traditional Chinese architectural motif, is integral to the China 2020 reforms (Figure 2). ${ }^{25}$ The beams are the major systems that include medical services, public health services, medical security, and pharmaceutical supply. The eight columns represent functions and conditions: management, auditing and governance, operations, innovation and professional talent, financing, informatics, pricing, and law. ${ }^{26}$ 


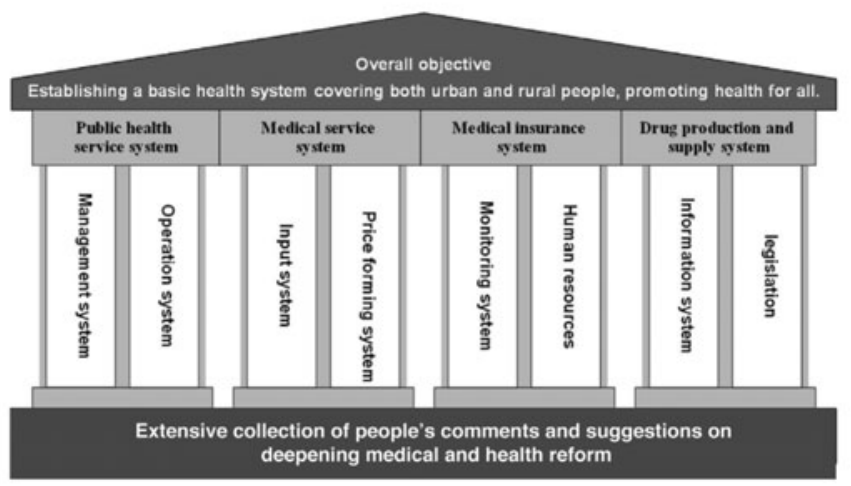

Fig. 2. Health system reform plan for China.

\section{Challenges to public health education in China}

Public health education in China has a long history that has been both deeply responsive to the unique needs and traditions of its people and extremely sensitive to global influences. Further commitments from educational leadership and local communities are essential in ensuring that public health education remains a top priority. Public health schools need to gain resources, stature, and recognition to successfully reform training tracks. While ongoing health reform provides opportunities for communityoriented care, the primary care workforce is often employed in different parts of the system that are not focused on public health. Effective horizontal programs for community care will require multisectoral cooperation between many vertical systems, including family planning, maternal and child health, and chronic diseases, among others. In order to create successful community-based systems, broader conceptions of public health integrating biological, social, and psychological aspects of improving health are needed. ${ }^{25}$ This integration also requires high-level support at the level of the Ministry of Health and Ministry of Education to ensure that public health education continues to advance.

\section{PUBLIC HEALTH EDUCATION IN INDIA}

In India, ancient practices of wellness such as ayurvedic medicine and yoga have been documented since about 1000 years BCE. The term ayurveda means 'science of life,' and it deals elaborately with measures for healthful 
living during the entire span of life. The practice of yoga is documented in the ancient Rig-Veda texts (ca. 5000 BCE) as not only spiritual discipline, but also health enhancing. These ancient health methods are practiced individually today, while the country rapidly moves towards modernization. In the mid- $20^{\text {th }}$ century, India emerged as a partitioned nation, a country made up of multiple states each with their unique language, literature, culture, cuisine and customs, but also a united independent and proud nation. It initially protected its development and modernization, and recently has seen rapid developments in infrastructure, economical and health indicators. Its public health education systems have taken a medical training viewpoint, which has led it down a different path than China.

\section{History of Public Health Training in India}

Formal public health activities in colonial, pre-independence India were backed by the introduction of physicians with both clinical and public health responsibilities. The public health workforce was constituted by personnel from medical and non-medical backgrounds that included auxiliary nurse midwives, nurses, midwives, traditional birth attendants, sanitary inspectors, sanitary assistants, health officers and physicians. ${ }^{28} \mathrm{~A}$ new government department to cater to education and health was created in 1912, with public health physicians in medical colleges entrusted with teaching hygiene. ${ }^{28}$

A School of Tropical Medicine was established in 1922 at Kolkata in eastern India. The establishment of this school marked a conscious shift from medical to a public health school. The All India Institute of Hygiene and Public Health (AIIH\&PH) - Kolkata was established in December 1932 and is the oldest school of public health in Southeast Asia. ${ }^{29}$ The institute was established with a generous donation from the Rockefeller Foundation with an objective to develop health manpower by providing postgraduate (training) facilities of the highest order and to conduct research directed towards the solution of various problems of health and diseases in the community.

The Health Survey and Development (Bhore) Committee report of 1946 is a milestone in Indian public health activities that is credited with shaping the present Indian health system. The recommendations of this committee suggested that all levels of health care must integrate the curative and preventive aspects of health care. ${ }^{30}$ In addition to specifying the population to be covered by the primary and secondary levels of health care, this report also advocated three months of training in preventive and social medicine for physicians as an integral part of the medical education system. This was deemed necessary for creating social physicians. 
The Department of Preventive and Social Medicine (also known as Community Medicine in some medical colleges) is an essential part of every medical college, and is entrusted with the task of orienting the medical students to the basic tenets of public health. These departments were established nationwide based on the recommendations of the 1955 Medical Education Conference. ${ }^{31}$ Medical students and interns were deployed to preventive and health promoting assignments in urban as well as rural settings. This compulsory rotation continues now with the expectation to cultivate a community orientation among junior physicians.

The ambitious plans for public health services envisioned by the Bhore Committee were not immediately realized and a circumspect Shrivastava Committee Report in 1975 stated that due to the "essentially urban orientation of medical education in India... the failure of the programmes of training in the fields of nutrition, family welfare planning, and maternal and child health...(and) the deprivation of the rural communities of doctors," there was a "need to re-orient undergraduate medical education to the needs of the country, with emphasis on community rather than on hospital care, and the importance of integrating various aspects of family planning with medical education." 32 The committee noted that the "role of the general practitioner is far from the treatment of sickness and the prevention of disease, but extends to include the social and cultural problems that contribute to the fabric of health." It went on to recommend the content, structure and process of change in order to reposition medical education across the country.

The Government of India launched the Re-Orientation of Medical Education (ROME) scheme in 1977 across the country ${ }^{33}$ to involve medical colleges by encouraging the adoption of preventive and curative health care in community development blocks (areas), subsequently to cover the entire district. ${ }^{31}$ This was meant to provide the much-needed link between medical colleges and communities, being mutually beneficial to both by linking health care provision and referral for the community along with an opportunity for medical colleges to acquaint medical graduates to rural communities. However, the scheme met with limited success in a few select institutions where it could orient medical students towards rural health. Medical graduates from most medical colleges still finish with the same pattern of education, which was present earlier, with more focus on curative medicine and an urban oriented approach. ${ }^{34}$

An Expert Committee for Health Manpower Planning, Production and Management was constituted in 1985 to provide an assessment of existing and projected national health manpower requirements at the primary and the intermediate level health care programs, and also to recommend the 
essential educational institutions and facilities to facilitate the production of appropriate categories of health manpower. ${ }^{35}$ The Expert Committee on Public Health Systems formed by the Ministry of Health and Family Welfare, Government of India in $1996^{36}$ and the Voluntary Health Association of India (VHAI) Independent Commission on Health in India $1997^{37}$ both recommended strengthening public health training. The latter also stressed the need to open new schools of public health in addition to efforts to strengthen the existing schools.

The Calcutta Declaration on Public Health was adopted at the Regional Conference on Public Health in South East Asia in the $21^{\text {st }}$ Century in November 1999. ${ }^{38}$ The conference was held against the background of an unfinished agenda of existing health concerns. In addition to the promotion of public health as a discipline and an essential requirement for health development, a leadership role for public health, the declaration stressed the primacy of creating career structures at the national, state, provincial and district levels. It also called for mandating competent background and relevant expertise for persons responsible for the health of populations. The resolution also emphasized the need to strengthen and reform public health education, training and research, as supported by the networking of institutions and the use of information technology for improving human resources development.

More recently, in 2006, the Prime Minister of India, Dr. Manmohan Singh, launched the Public Health Foundation of India (PHFI) as a concerted action towards addressing the supply-side deficiencies in human resources in health in India. ${ }^{39}$ The Foundation has a mandate to establish new institutes of public health, assist the growth of existing public health training institutions, establish a strong national research network, generate policy recommendations and develop a vigorous advocacy platform.

\section{Current Public Health Training in India}

India currently has 335 licensed medical colleges offering the Bachelor of Medicine and Bachelor of Surgery (MBBS) degree in India. Over 40 percent of these colleges are run by the government (central, state or municipal corporations). These 335 medical colleges are unevenly distributed, with more colleges situated in southern and western parts of the country, which are more urban. A total of 184 medical colleges offer an MD (Community Medicine/ Preventive and Social Medicine) degree in India with total annual intake of 602 students. This number is woefully inadequate for the second most populous country in the world. In addition to the postgraduate degree, 39 medical colleges also offer a Diploma in 
Public Health with an annual intake of about 140 doctors. In addition, six colleges offer a Diploma in Community Medicine with an intake capacity of 13 candidates. A few select institutions also offer specialized courses in public health like MD in Community Health Administration (National Institute of Health and Family Welfare (NIHFW) - Delhi), MD in Tropical Medicine (West Bengal University of Health Sciences - Kolkata), MD in Hospital Administration (offered by six universities)* and $\mathrm{PhDs}$ in Community Medicine and in Hospital Administration (All India Institute of Medical Sciences, New Delhi). However, the intake capacity of these courses is limited.

In addition to the medical colleges offering basic and specialized training in Community Medicine/ Preventive and Social Medicine, there are 23 institutes currently offering a Master in Public Health. The establishment of these institutes is a relatively new initiative, and it provides opportunities for non-medical graduates to obtain educational qualifications in public health. These institutes have the capacity to enroll approximately 573 candidates annually and offer a wide variety of skills covering essential public health domains. While most courses are generic public health courses, some offer a master's degree targeting specific skills like Master in Public Health in Field Epidemiology (National Centre for Disease Control - New Delhi), Master of Public Health in Social Epidemiology, Master of Public Health in Health Policy, Finance and Economics (Tata Institute of Social Sciences - Mumbai) and Master of Public Health in Health Services Management (National Institute of Epidemiology - Chennai).

As mentioned above, AIIH\&PH - Kolkata is the oldest school of public health in Asia. Another institute offering public health courses is NIHFW - Delhi. NIHFW is an apex technical institute, funded by the Ministry of Health and Family Welfare, for promoting health and family welfare programs in the country through education, training, research, evaluation, consultancy and specialized services.

As mentioned, PHFI was launched in 2006. The Indian Institutes of Public Health established by the Foundation are not only engaged in the delivery of long-term academic programs in vital public health areas, but also in health system strengthening through short-term trainings and program and policy relevant research. PHFI also has a mandate to facilitate the creation of accreditation systems for public health education. In the

\footnotetext{
* Narayana Medical College, Nellore; Nizam's Institute of Medical Sciences, Hyderabad; Sher-I-Kashmir Instt. Of Medical Sciences, Srinagar; Kasturba Medical College, Manipal; Vydehi Institute Of Medical Sciences \& Research Centre, Bangalore; and Armed Forces Medical College, Pune.
} 
short interval since its inception in 2006, the foundation has engaged in several initiatives of national and international acclaim through a network of four Indian Institutes of Public Health at Gandhinagar, Hyderabad, Delhi and Bhubaneshwar.

\section{Public Health Education in India Needs to Adapt to the Changing Environment}

A predominantly medical model, which has totally dominated public health education in India is insufficient to answer the large public health concerns of the magnitude the country needs. Public health professionals with a medical background alone cannot address the severe shortage of public health personnel in the country. There is a growing recognition that public health is a multidisciplinary field, requiring input from social workers, psychologists, and others. Successful public health interventions necessarily come from teamwork and involve an extensive and continual engagement between the community and the health team. Good health is dependent upon a wide range of fields that encompass economics, equity, education, empowerment and social justice. Addressing these multiple dimensions is not possible for any one single profession and would need team work in policy formulation, administration and service delivery to the beneficiaries.

\section{Networking of Public Health Institutions in Education in India}

A success story in Indian public health education has been the initiation of a one-year Post-Graduate Diploma program in Public Health Management. The National Rural Health Mission (NRHM) in India has envisioned the creation of public health managers who would oversee a range of functions, including community-based disease surveillance, program planning, implementation, monitoring and evaluation. This capacity generation is critical at all levels of the health system in order to meet the Millennium Development Goals (MDG) targets based on a primary health care approach. However, there is a shortage of qualified public health professionals across all levels of the health system. As part of the NRHM and Indian Public Health Standards (IPHS) guiding principles, the central as well as state level governments expressed an urgent need for such professionals to be recruited and positioned in the health system across all levels.

The Post-Graduate Diploma program in Public Health Management was launched by the NRHM to impart the knowledge and skills relevant to public health management. The program is structured on a multidisciplinary curriculum. The partner institutions defined the competencies that must be possessed by the students upon their graduation and regularly meet to 
review their progress towards this objective. Skill based curriculum models and instructional methods have been adopted as the method of choice for these health professionals. Nine public health institutions have established this program and plan to train 175-200 health professionals per year.*

The NIHFW has developed a Public Health Education \& Research Consortium (PHERC) to link individuals and organizations in order to develop strategies for greater involvement of partner institutions in national public health programs through capacity building for education and research. This consortium links medical colleges, State Institutes of Health and Family Welfare, Health and Family Welfare Training Centers, nursing schools and non-governmental organizations (NGOs) to pool all available human resources, thus presenting an excellent opportunity to engage in public health education initiatives.

Finally, the South East Asia Public Health Education Institutions Network (SEAPHEIN) has been developed and promoted under the stewardship of the World Health Organization's South-East Asia Regional Office (WHO SEARO), to promote and strengthen public health education and training in the member countries. The Indian chapter of SEAHPEIN, India Public Health Education Institution Network (IndiaPHEIN) established in July 2010 has the mission to collaborate with Indian member institutes in partnership to improve and sustain the quality and relevance of public health education to address the increasing challenges of health improvement in the country. It thus provides another platform for institutes engaged in public health education to share experiences and resources with each other.

\section{Challenges to public health education in India}

\section{Governance and accreditation issues in public health education}

Public health teaching and training programs are currently offered to both medical and non-medical public health professionals in the public and the private sector in India. The Medical Council of India (MCI) is a statutory body charged with the responsibility of establishing and maintaining uniform standards of medical education and recognition of medical qualifications and it also ensures the ethical practice of medicine by all registered medical practitioners. ${ }^{40}$ It is important to note that its mandate

\footnotetext{
* AIIH\&PH - Kolkata; Mahatma Gandhi Institute of Medical Sciences - Wardha (MGIMS); Indian Institute of Public Health - Gandhinagar; Indian Institute of Public Health - Delhi; Post Graduate Institute of Medical Education and Research - Chandigarh; Jawaharlal Institute of Postgraduate Medical Education and Research - Puducherry; Indian Institute of Public Health - Hyderabad; Indian Institute of Public Health - Bhubaneshwar; and NIHFW - New Delhi.
} 
covers only medical education across the country. Therefore, only the public health degrees granted by medical colleges (MD, DPH/ DCM, PhD) come under the purview of MCI. The public health courses for non-medical professionals are not overseen by MCI and may be registered under the All India Council for Technical Education (AICTE) or the University Grants Commission (UGC). This creates a situation where there is no single uniform overarching body or council responsible for public health education in the country as a whole.

The issue of accreditation is vital, not just for medical colleges, but even more so with the establishment of newer institutes offering training in public health. ${ }^{41}$ Accreditation should be seen as an essential step towards the improvement and standardization of teaching programs as well as the establishment of competencies. In the absence of an overarching body responsible for all public health education, accrediting public health courses is a big challenge. Success stories of developing countries and replicable models should be considered and a set of checks and balances is necessary through a single council that covers conventional public health training for medical students and the public health training for the master's programs.

\section{Need for specialized courses}

The current public health model in medical colleges is comprehensive and equips students with general public health skills. However, specialized domains such as epidemiology, biostatistics, health management, occupational and environmental health, public health nutrition and social science methods have necessitated the presence of specialized courses for public health practitioners. These specialized areas have witnessed rapid advances and are vital to the delivery of health interventions. However, there is a dearth of trained manpower in these areas. The initiation of Master of Public Health programs with specialized tracts is a step in this direction. Assessing the need and demand for these professionals has been undertaken in some $\operatorname{areas}^{42,43}$ and is an urgent necessity for manpower planning.

\section{A need-demand paradox}

While it is widely acknowledged that there is a felt need for a higher number of public health professionals, there are limited job opportunities for graduates from the educational institutes for public health within the government sector. This leads to fewer students opting for public health courses in spite of a felt need for public health professionals. Urgent intervention in the form of facilitating the creation of a public health cadre 
in the state health services is necessary. This will provide opportunities for all public health professionals, with either a medical or a non-medical background, in the health system. We need to simultaneously create job opportunities and design career pathways for trained public health professionals.

\section{CONCLUSION}

India and China, the most populous countries in the world, are experiencing rapid economic development and modernization. Both countries have made great strides in public health education systems over the past several decades. However, much remains to be done.

India's public health situation is currently much worse than China's, with higher infant and maternal mortality and limited expenditure on health (Table 2). India suffers from excess mortality and morbidity from preventable communicable and non-communicable diseases. Its infrastructure lacks trained public health personnel and its public health education model, based in medical schools, is inadequate to meet the needs of the country. Issues for consideration include the establishment of independent schools of public health, separate from medical institutions, with multidisciplinary faculty and a student body with both undergraduate and postgraduate training capacities. These schools need to rise to the high international standards set by schools of public health in the US, Europe and Australia.

China's public health status is far stronger than India's and it has benefitted from the universal system developed with barefoot doctors and universal health coverage systems in the last half of the $20^{\text {th }}$ century. However, the current situation also requires schools of public health achieving recognized international standards to provide the leadership, research and advocacy necessary to meet the new challenges of public health in a rapidly changing society.

Greater support from both countries' respective governments and institutional networks has contributed to the development of more mature and formalized systems. There are still unmet needs in both nations with respect to public health education and infrastructure for absorbing trained health professionals, and great opportunities for expanding public health education to meet the evolving needs of the regions. It is time that these two rapidly developing countries invest in their public's health by properly educating their health professionals. 


\section{Acronyms List:}

AIIH\&PH $=$ The All India Institute of Hygiene and Public Health

$\mathrm{CDC}=$ Center for Disease Control and Prevention (China)

MCI $=$ The Medical Council of India

NIHFW $=$ The National Institute of Health and Family Welfare (India)

NRHM $=$ The National Rural Health Mission (India)

PHFI = The Public Health Foundation of India

PUMC $=$ Peking Union Medical College

SEAPHEIN $=$ The South East Asia Public Health Education Institutions Network

Acknowledgements: Thanks to Dr. Lincoln Chen for helpful comments on the history and practice of public health education in China.

Conflicts of Interest: None declared.

\section{REFERENCES}

1. Veith I. The yellow emperor's classic of internal medicine. Berkeley, CA: University of California Press; 2002.

2. Wong KC, Wu L-t. History of Chinese medicine; being a chronicle of medical happenings in China from ancient times to the present period. 2nd ed. New York, NY: AMS Press; 1973.

3. Benedict C. Policing the sick: plague and the origins of state medicine in late imperial China. Late Imperial China. 1993;14:63.

4. Yip KC. Health and national reconstruction in nationalist China: The Development of Modern Health Services, 1928-1937. Ann Arbor, MI: The Association of Asian Studies; 1995.

5. Bu L. Starting a public health education movement in China: "The Council on Health Education," 1915-1926. Launching Chinese public health. Johns Hopkins University; 2008.

6. Fee E, Bu L. Models of public health education: choices for the future? Bull World Health Organ. 2007;85:977-9.

7. Bu L, Fee E. John B. Grant international statesman of public health. Am J Public Health. 2008;98:628-9.

8. Cohen MS, Henderson GE, Aiello P, Zheng H. Successful eradication of sexually transmitted diseases in the People's Republic of China: implications for the 21st century. J Infect Dis. 1996;174:S223-9.

9. Zhang D, Unschuld PU. China's barefoot doctor: past, present, and future. Lancet. 2008;372:1865-7.

10. Lampton DM. The politics of medicine in China : the policy process, 19491977. Boulder, CO: Westview Press; 1977.

11. World Bank World Development Report, Table 3.1 Global Health Expenditure; 1993.

12. Hsiao W. The Chinese health care system: lessons for other nations. Soc Sci Med. 1995;41:1047. 
13. Hesketh T, Zhu WX. Health care in China: maternal and child health in China. BMJ. 1997;314:1898-9.

14. Griffiths SM. Leading a healthy lifestyle: the challenges for China. Asia Pac J Public Health. 2010;22:110S.

15. Liu Y. China's public health-care system: facing the challenges. Bull World Health Organ. 2004;82:532-8.

16. Wang H, Wang N, Bi A, Wang G, Ding G, Jia M, et al. Application of cumulative odds logistic model on risk factors analysis for sexually transmitted infections among female sex workers in Kaiyuan City, Yunnan Province, China. Sex Transm Infect. 2009;85:290-5.

17. Lin CC, Gao X, Chen XS, Chen Q, Cohen MS. China's syphilis epidemic: a systematic review of seroprevalence studies. Sex Transm Dis. 2006;33:72636.

18. Griffiths SM, Li LM, Tang JL, Ma X, Hu YH, Meng QY, et al. The challenges of public health education with a particular reference to China. Public Health. 2010;124:218-24.

19. Zhu MJ, Jin MJ, Chen K. Discussion of public health system and public health education. Zhejiang Prev Med. 2004;16:60e1.

20. Wei B, Lu L, Zhang ZY, Ma ZY. Bridging the gap between education and practice in public health, with particular reference to less-developed provinces in China. Public Health. 2011;125:25-9.

21. Li LM. The Current State of Public Health in China. Annu Rev Public Health. 2004;25:327-39.

22. CCDC. Chinese Center for Disease Control and Prevention brief introduction. Beijing; 2003.

23. APACPH. Asia Pacific Academic Consorium for Public Health. 2010. Available from URL: http://www.apacph.org/index.html (Accessed 20 September, 2011).

24. Zhang D, Mou J, Cheng JQ, Griffiths SM. Public health service in Shenzhen: a case study. Public Health. 2011;125:15-9.

25. Li LM, Tang JL, Lu L, Jiang Y, Griffiths SM. The need for integration in health sciences sets the future direction for public health education. Public Health. 2011;125:20-4.

26. Central Committee of the Communist Party of China and State Council. Guidelines on deepening the reform of the healthcare system. Beijing: Central Chinese Government; 2009.

27. Liang KY, Zeger SL. Regression analysis for correlated data. Annu Rev Public Health. 1993;14:43-68.

28. Datta KK. Public health workforce in India: career pathways for public health personnel. New Delhi; 2009.

29. All India Institute of Hygiene and Public Health. Available from URL: http:// www.aiihph.gov.in/html/about_us.htm (Accessed 18 November, 2010).

30. NIHFW. Committee and Commission. Available from URL: http://nihfw.org/ NDC/DocumentationServices/Committe_and_commission.html (Accessed 18 November, 2010). 
31. Thakur HP, DD Pandit, Subramanian P. History of preventive and social medicine in India. J Postgrad Med. 2001; 47(4): 283-5.

32. Health services and medical education: A programme for immediate action (Shrivastav Committee Report). 1975.

33. Poulose KP, Natarajan PK. Re-orientation of medical education in India: past, present and future. Indian J Public Health. 1989;33:55-8.

34. Sathe P, Sathe A. Epidemiology and Management For Health Care For All, 1st ed. Mumbai: Popular Prakashan Pvt. Ltd.; 1991.

35. Expert review committee for health manpower planning, production and management (Bajaj Committee). 1986. Available from URL: http://nihfw. org/NDC/DocumentationServices/Reports/Bajaj\%20Committee\%20report. pdf (Accessed 18 November, 2010).

36. Expert Committee on Public Health Systems. 1996. Available from URL: http:// nrhm-mis.nic.in/ui/who/PDF/Expert Committee on PH System JS Bajaj 1996.pdf (Accessed 6 December, 2010).

37. Voluntary Health Association of India. Report of the Independent Commission on Health in India. New Delhi: VHAI; 1997.

38, (No author). Regional Conference on Public Health in South East Asia in the $21^{\text {st }}$ Century, Calcutta, 22-24 November 1999: "Calcutta Declaration on Public Health". J Epidemiol Community Health. 2000;54:749.

39. World Health Organization. Working together for health: The World Health Report. Geneva; WHO: 2006.

40. Medical Council of India. Available from URL: http://www.mciindia.org/ (Accessed 18 November, 2010).

41. Garg BS. Accreditation of public health courses in India - the challenge ahead. Indian J Community Med. 2004;29:52.

42. Zodpey SP, Negandhi H, Tiwari RR. Mapping ‘Occupational Health’ courses in India: a systematic review. Indian J Occup Environ Med. 2009;13:135-40.

43. Sharma K, Zodpey S. Need and opportunities for health management education in India. Indian J Public Health. 2010;54:84-91. 